\title{
A pesquisa sobre política de indexação no Brasil: avanços e desafios
}

La investigación sobre políticas de indización en Brasil: avances y desafíos

Research on indexing policy in Brazil: progress and challenges

Paula Regina DaL'Evedove (1), Mariângela Spotti Lopes FuJITA (2)

(1) Universidade Federal de Pernambuco/UFPE. Av. da Arquitetura, s/n, Campus Universitário, CEP 50740-550 - Recife/PE, p.dallevedove@gmail.com (2) Universidade Estadual Paulista, Av. Hygino Muz-zi Filho, 737, Campus Universitário, CEP. 17525900, Marília, SP, Brasil, mariangelasIf57@gmail.com

\begin{abstract}
Resumen
El objetivo de este estudio es reflexionar sobre la investigación brasileña sobre políticas de indización en el área de Organización y Representación del Conocimiento. A través de la investigación exploratoria bibliográfica, hemos tratado de contextualizar los principales avances en la literatura sobre la política de indización y, sobre todo, facilitar la comprensión del estado actual de la investigación sobre el tema. Se observó que, a pesar de los avances y resultados consistentes obtenidos por la investigación brasileña, debe prestarse atención urgente a nuevos enfoques de investigación que se centran en las cuestiones que permanecen abiertas o que no se han trabajado a fondo hasta el momento.
\end{abstract}

Palabras clave: Indización. Políticas de indización. Organización del conocimiento. Representación del conocimiento. Brasil.

\section{Introdução}

As diretrizes e normas adotadas no processo de indexação servem para dar direcionamento às ações profissionais, visando potencializar a condição de êxito dos sistemas de informação no que tange à criação da informação documentária e sua posterior recuperação. A expressiva importância de uma política de indexação estruturada e registrada para o encaminhamento da atividade de indexação decorre, especificamente, por esta direcionar a prática profissional mediante embasamento teórico e por compilar um conjunto de diretrizes e critérios elaborados e adaptados à realidade das unidades de informação.

Inserida na esfera da representação e recuperação da informação, a política de indexação constitui-se na formalização dos processos, procedimentos, instrumentos e filosofias institucionais, podendo ser entendida como a iniciativa de materializar em guias ou manuais os procedimentos adotados para o desenvolvimento da atividade de indexação (Gil Leiva, 2008). Neste sentido, a adoção de políticas de indexação é

\begin{abstract}
The aim of this study is to reflect about the Brazilian research on indexing policy within the Organization and Knowledge Representation filed. Through a bibliographical exploratory research, we sought to contextualize the main advances in the literature on indexing policy and, above all, provide an understanding of the current state of the art. It was observed that, despite the advances and consistent results obtained by the Brazilian researchers, it is urgent to focus on new research approaches that look at the issues that remain open or that have not been worked in depth up to now.
\end{abstract}

Keywords: Indexing. Indexing policy. Knowledge organization. Knowledge representation. Brazil.

uma ação necessária para o bom funcionamento do sistema de recuperação de informação, produzindo uma correspondência precisa entre as ações profissionais e a qualidade dos produtos e serviços informacionais resultantes do processo.

Ao versar sobre a política de indexação, verifica-se ser esta uma temática pouco trabalhada pela literatura especializada em Ciência da Informação. No Brasil, as discussões acerca das políticas de indexação são recentes, sendo encabeçadas no contexto científico com o estudo intitulado Diretrizes para uma política de indexação apresentado por Marília Vidigal Carneiro no ano de 1985. A partir de então, a temática passou a ser trabalhada paulatinamente no âmbito da área de Organização e Representação do Conhecimento.

Diante disso, o presente estudo comporta uma discussão reflexiva acerca da pesquisa brasileira sobre política de indexação. Esta comunicação convida-nos a pensar sobre os avanços alcançados pela literatura especializada e, sobretudo, propicia uma compreensão do atual 
cenário investigativo sobre a temática. Para isso, realizou-se um estudo exploratório de revisão bibliográfica, a fim de demonstrar o estado da arte sobre a questão.

\section{Políticas de indexação}

A política de indexação é considerada um contributo efetivo para o bom desempenho do sistema de recuperação de informação, atrelando questões inerentes à prática profissional no processo de indexação e questões de gestão, as quais versam para o contexto administrativo da unidade de informação enquanto instituição.

A atuação estratégica das unidades de informação está diretamente atrelada ao bom encaminhamento de uma política de indexação. Isto porque, ao atuar como um recurso auxiliar de orientação ao bibliotecário indexador, o estabelecimento de uma política de indexação não está condicionado apenas aos aspectos que perpassam o fazer técnico, mas, sobremaneira, às questões organizacionais presentes nos mais variados contextos informacionais.

A função da política de indexação é definir as variáveis que influenciam o desempenho da atividade de indexação, tendo por objetivos "[...] estabelecer princípios e critérios que servirão de guia na tomada de decisões para otimização do serviço, racionalização dos processos e consistência das operações nele contidas [...]" (Carneiro, 1985, p. 222). Na ótica de Almeida (2000), as políticas ou diretrizes administrativas figuram na qualidade de planos gerais de ação que orientam na tomada de decisão ao estabelecerem guias mestras, o que confere estabilidade à instituição. Desta forma, no que tange à política de indexação, a questão administrativa da unidade de informação torna-se um aspecto indispensável a ser considerado quando do estabelecimento destas diretrizes.

Contudo, o contributo destas diretrizes não está relacionado apenas às questões organizacionais. A política de indexação atua como um recurso valioso na busca pela qualidade dos produtos e serviços informacionais disponibilizados nos sistemas de recuperação de informação, uma vez que proporciona equilíbrio entre o saber científico e a prática da profissão no que tange ao tratamento temático da informação. Consequentemente, contribui para a motivação e autonomia durante a realização do processo de indexação por propiciar segurança ao bibliotecário indexador no decorrer da atividade, contribuindo para a superação de barreiras que possam existir entre o tripé composto por teoria, prática cotidiana da profissão e ca- racterísticas e especificidades da unidade de informação.

Rubi (2004, 2008) entende que a política de indexação é uma aliada para que o bibliotecário indexador realize sua tarefa profissional de maneira "racional e objetiva", sendo indispensável que os profissionais bibliotecários percebam a importância da indexação em todo o ciclo documental. Para tanto, a autora advoga sobre a necessidade da política de indexação ser considerada parte administrativa da unidade de informação, como uma etapa de reflexão propriamente dita. Isto é, estas diretrizes não devem ser vistas como uma lista de procedimentos, e sim uma filosofia que reflita os interesses e objetivos da organização, o que exige do bibliotecário indexador uma efetiva compreensão de que a atividade de indexação exige parâmetros que o guiem no momento de tomada de decisão, minimizando subjetividades e incertezas.

Complementando o exposto, tem-se o fato da unidade de informação ser composta por partes interligadas que versam para um objetivo comum, o de disponibilizar a informação de modo a satisfazer as necessidades informacionais dos usuários. Esta visão indica que a indexação e sua política são uma das partes que compõem os sistemas de recuperação de informação. Com efeito, precisam integrar o planejamento global de toda e qualquer unidade de informação, como um parâmetro de sua administração no contexto gerencial.

Outro ponto importante a ser considerado é o de que a política de indexação condiciona os resultados de uma estratégia de busca por parte do usuário, o que produz uma exata correspondência com o assunto pesquisado em índices.

A política decide não só sobre a consistência dos procedimentos de indexação em relação aos efeitos que se necessita obter na recuperação, mas, principalmente, sobre a delimitação de cobertura temática em níveis qualitativos e quantitativos tendo em vista os domínios de assuntos e as demandas dos usuários. Isso nos leva a pensar sobre a indexação do ponto de vista gerencial e estratégico no contexto de unidades de informação, haja vista ter efeitos na entrada e na saída de informações do sistema (Fujita, 2012a, p. 17).

Carneiro (1985) sinaliza que no momento de se formalizar os elementos básicos para a constituição de uma política de indexação, três requisitos são indispensáveis para o bom planejamento de um sistema de recuperação de informação, quais sejam: identificação da organização à qual está relacionado o sistema de 
indexação; identificação dos usuários ao qual se destina o sistema; e por fim, mas não menos importante, figuram os recursos humanos, materiais e financeiros envolvidos no processo. Rubi (2008) compreende que estes fatores ou requisitos podem ser delimitados em:

1. Contexto: conhecer os objetivos e atividades da instituição é fundamental para determinar o tipo de serviço a ser implantado, pois, além do tipo de atividade da organização afetar a demanda de informação, determina qual sistema de indexação a ser utilizado e os níveis de exaustividade e especificidade exigidos.

2. Destinatário: a principal finalidade de um sistema de recuperação de informação é o fornecimento de informação precisa aos usuários, em que identificar a clientela é um pré-requisito fundamental para o planejamento de qualquer sistema de informação. $A$ partir de um estudo de usuários serão obtidas informações sobre o conhecimento do alcance exigido pelo sistema quanto aos assuntos centrais e periféricos e quanto aos níveis de tratamento exigidos; o núcleo de um vocabulário que refletirá os interesses do trabalho e necessidades de informação da clientela do sistema; conhecimento do tipo de resposta do sistema; e conhecimento do nível de exaustividade exigido na indexação, o grau de especificidade necessária, a linguagem de indexação e o nível de sofisticação desejável do sistema.

3. Infraestrutura: no qual serão considerados todos os recursos humanos, materiais e financeiros envolvidos no processo.

Atrelando o ciclo documental à política de indexação, Kobashi (1994) indica que tais diretrizes estão relacionadas às características do sistema documentário: necessidades do usuário; instituição onde se desenvolve; domínio do assunto tratado; recursos humanos, físicos e financeiros; produtos e serviços; e relação custo/desempenho.

Observa-se que tais indicações apontam a política de indexação como uma ação indispensável a ser desenvolvida e considerada no âmbito da administração de toda e qualquer unidade de informação, ao passo que reflete de forma integrada e interdependente os objetivos e peculiaridades das atividades de organização, disponibilização e uso da informação (Cesarino \& Pinto, 1978). Além da interdependência de seus elementos, a implementação de uma política de indexação pressupõe uma constante avaliação, visto que suas diretrizes estão diretamente relacionadas a um conjunto de fatores que são, por natureza, suscetíveis de alterações, por razões relativas à atualização do acervo, possíveis mudanças das áreas de interesse da unidade de informação, perfis dos usuários, linguagens de indexação, dentre outros.

Sendo assim, tem-se a necessidade da política de indexação estar registrada e compor o manual de indexação, pois algumas incoerências cometidas durante o processo de tratamento temático da informação são resultantes da ausência de políticas e manuais próprios para o contexto de bibliotecas universitárias que sirvam como diretrizes para o trabalho do profissional e, sobretudo, como instrumento para a sua formação em serviço (Rubi, 2008; Dal' Evedove, 2014).

Ao sistematizar a política de indexação para um sistema de armazenamento e recuperação de informação, Carneiro (1985) evidencia dois eixos ou planos integrantes (Figura 1):

- Eixo horizontal: contempla atividades de gestão onde estão os requisitos para o bom planejamento de um sistema de recuperação de informação; e

- Eixo vertical: contempla as atividades de organização e representação da informação que reúne um conjunto de elementos e variáveis que afetam a atividade de indexação.

No eixo horizontal, entende-se que as atividades de gestão englobam toda e qualquer prática administrativa que vise ao alcance dos objetivos institucionais. Isto implica considerar a gestão de processos organizacionais resultantes da atividade humana. Por sua vez, no eixo vertical, os principais elementos a serem contemplados na política de indexação dizem respeito à cobertura de assuntos, seleção e aquisição de documentos-fonte, processo de indexação, estratégia de busca, tempo de resposta do sistema, forma de saída e avaliação do sistema. Neste eixo, as variáveis correspondem aos aspectos que interferem no processo de indexação e que influem na recuperação da informação, sendo estas: exaustividade, especificidade, escolha da linguagem, revocação e precisão (CARNEIRO, 1985).

Pode-se inferir que as duas visões de política de indexação apresentadas pela referida autora são complementares, em que se observa uma visão mais ampla,

[...] que considera o contexto da gestão de sistemas de recuperação da informação sobre as atividades de indexação e a visão mais direcionada aos procedimentos e elementos de indexação circunscritos ao manual de indexação, sua operacionalização e avaliação (Fujita, 2012a, p. 22). 


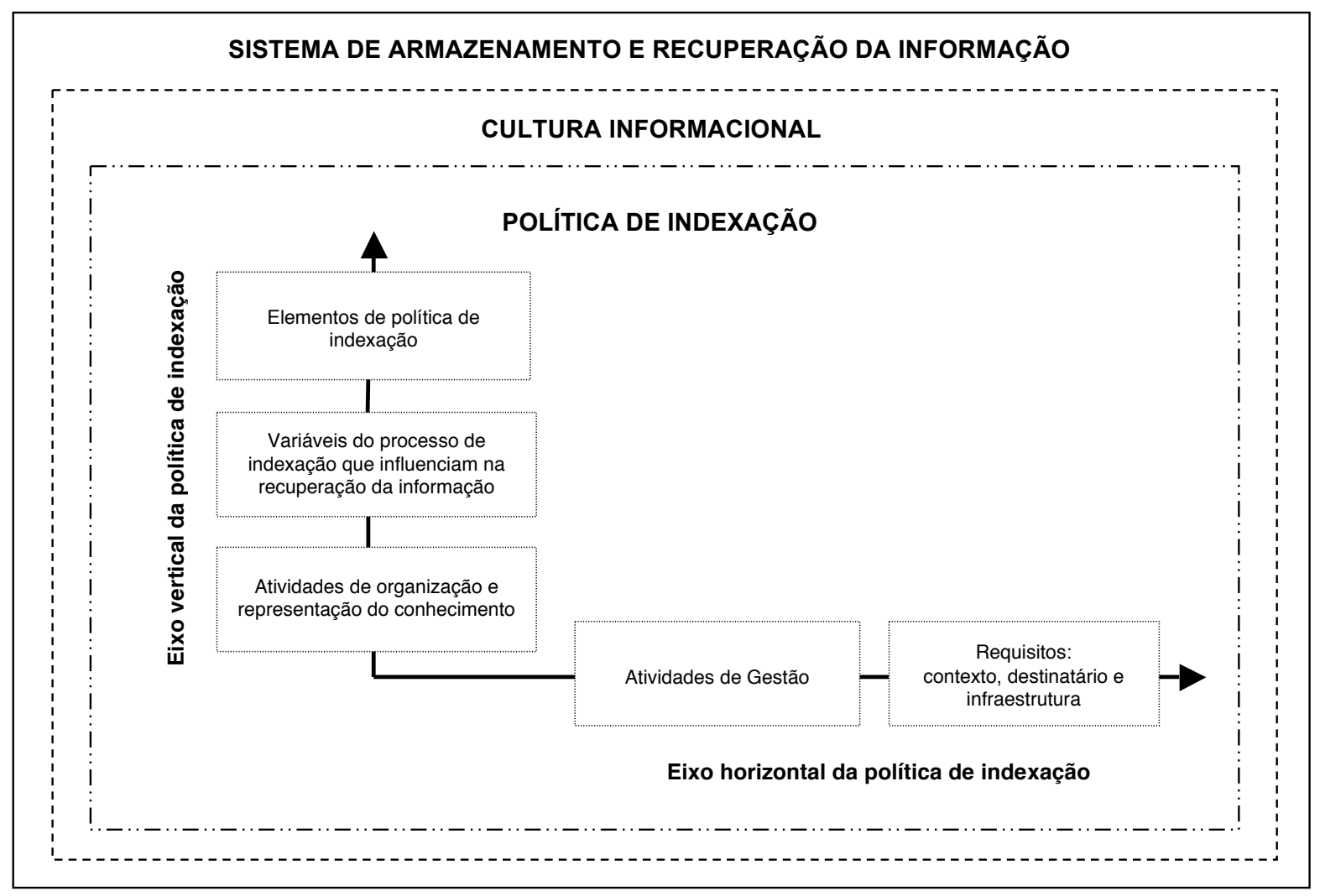

Figura 1: Eixos da política de indexação (Fonte: Elaborado a partir de Fujita, 2012a)

Com base neste binômio inerente ao sistema de recuperação de informação que reflete uma dupla dimensão (Guimarães, 2004), a política de indexação é vista como um conjunto de procedimentos, materiais, normas e técnicas orientadas por decisões, as quais refletem os princípios subjacentes da cultura organizacional de uma unidade de informação.

\section{A pesquisa brasileira na temática}

Carneiro (1985) é quem projeta as primeiras diretrizes para o estabelecimento de uma política de indexação no cenário nacional, tomandose como base os principais elementos envolvidos no planejamento de um sistema de recuperação de informação e a pouca literatura especializada que, segundo a própria autora era "bastante esparsa".

Tal cenário não mudou muito desde então e as pesquisas relacionadas ao tema ainda são limitadas, podendo-se citar em âmbito nacional os estudos de Albuquerque, Autran e Ramalho (2011); Albuquerque e Pereira (2007); Boccato (2012); Cervantes, Fujita e Rubi (2008); Dal'Evedove (2011 e 2014); Dal'Evedove e Fujita (2013); Fujita et. al. (2006a, 2006b e 2007);
Fujita (2012a, 2012b e 2012c); Fujita e Gil Leiva (2009, 2010 e 2012); Fujita e Rubi (2006a, 2006b, 2006c e 2007); Fujita, Rubi e Boccato (2009); Gonçalves, Fujita e Rubi (2006); Guimarães (2004); Kochani, Boccato e Rubi (2011); Lopes (2006); Lousada et al. (2011); Neves e Galvino (2010); Nunes (2004); Redígolo et al. (2012); Rubi (2000, 2004, 2008, 2010, 2012a e 2012b); Rubi et al. (2007); Rubi e Fujita (2003a; 2003b, 2006, 2007 e 2010); Rubi, Fujita e Boccato (2012a e 2012b) e Silva e Santos (2012), que em sua grande maioria fazem menção ao trabalho de Carneiro (1985) e buscam a sua maneira e dentro dos seus escopos investigativos contribuírem com referenciais que sirvam de orientação para a definição de diretrizes que norteiem a atividade de indexação.

\subsection{Caminhos percorridos}

Debruçando-se na literatura brasileira especializada sobre política de indexação, observa-se que, apesar de não serem numerosos, os estudos dedicados ao tema apresentam resultados bastante significativos, sendo em sua maioria verticalizados no assunto. 
Com base nos estudos de Carneiro (1985) e trabalhos subsequentes (Rubi, 2000, 2004; Rubi, Fujita, 2003 e Guimarães, 2004) sobre política de indexação, Rubi (2008) compila os principais elementos indicados para a elaboração destas diretrizes visando a sistematizar o conhecimento acerca do tema. Para tanto, apresenta uma proposta atualizada dos princípios de orientação para a elaboração de políticas de indexação. Neste estudo é apresentado à comunidade da área de Organização e Representação do Conhecimento um agrupamento dos elementos base a serem considerados na elaboração das políticas de indexação, no qual alia os elementos as suas fontes literárias (trabalhos em que tais indicações foram observadas).

O fruto deste estudo é uma proposta de diretrizes apresentada pela autora para a elaboração de política de indexação destinada à construção de catálogos cooperativos em bibliotecas universitárias, a partir da abordagem sociocognitiva com bibliotecários e usuários inseridos no contexto e da perspectiva conceitual dos aspectos teóricos que envolvem a indexação e a catalogação de assunto. $O$ contributo desta compilação advém da indicação de um conjunto de elementos que servem de orientação para a elaboração de diretrizes de política de indexação destinadas à atividade de indexação em bibliotecas universitárias.

Como forma de avançar na questão, Dal'Evedove (2014) recomenda a observância dos aspectos cognitivos, culturais e sociais inerentes ao processo de tratamento temático da informação no delineamento das políticas de indexação. Neste estudo, foram apresentadas oito diretrizes complementares a serem consideradas no momento da elaboração da política de indexação para o contexto de bibliotecas universitárias brasileiras.

Traçando uma perspectiva inovadora, o estudo voltou-se para a perspectiva humana do processo de tratamento temático da informação a qual perpassa as questões relativas à política de indexação. $O$ estudo apresentou novos subsídios a serem considerados no momento da elaboração de políticas de indexação para o contexto de bibliotecas universitárias, contribuindo sumariamente para tornar a política de indexação um recurso passível de uso por parte do profissional bibliotecário. Isto porque, foram consideradas as indicações e concepções teóricas; as especificidades da prática cotidiana da profissão relacionadas à atividade de indexação; e da realidade própria das bibliotecas universitárias, especificamente no que tange aos interesses informacionais dos usuários. $O$ diferencial frente a outros estudos que tiveram como pano de fundo a política de indexação assenta-se na observação dos modos sociais de pensamento dos atores testados, articulando suas opiniões, impressões, comportamentos e interesses pessoais e coletivos na busca por diretrizes que atendessem: os fundamentos teóricos e metodológicos presentes na área de Organização e Representação do Conhecimento; o contexto sociocognitivo do bibliotecário indexador; bem como as características e princípios culturais dos usuários (Dal' Evedove, 2014).

Tendo como preocupação central os aspectos organizacionais, Louzada et. al. (2011) voltaram-se para as relações existentes entre as políticas de indexação e a gestão do conhecimento em contextos organizacionais, como subsídio para a implementação de ações estratégicas. Como resultado, as autoras apontam as principais contribuições da gestão do conhecimento organizacional para as políticas de indexação, com vistas à construção do conhecimento. Ainda neste eixo investigativo, Rubi, Fujita e Boccato (2012) com a proposta de analisar os aspectos teóricos sobre política de indexação, sob a perspectiva do conhecimento organizacional, atestam a viabilidade da política de indexação ser elaborada a partir do conhecimento tácito do bibliotecário indexador produzido no contexto organizacional. Para tanto, o estudo é conduzida por meio da metodologia do Protocolo Verbal em Grupo (PVG), transformando o conhecimento tácito em conhecimento explícito na forma de manual de indexação.

Outro estudo bastante significativo na área foi o apresentado por Cervantes, Fujita e Rubi (2008) no qual são compiladas as terminologias relacionadas à política de indexação, mediante um estudo terminológico. Tendo um direcionamento mais pedagógico, Fujita e Gil Leiva (2012) oferecem uma rica contribuição à área de Organização e Representação do Conhecimento a partir da organização e publicação do livro intitulado "Política de Indexação" que aborda aspectos teóricos, metodológicos e pedagógicos sobre a da temática.

\subsection{Questões em aberto}

Grande parte dos estudos desenvolvidos no âmbito nacional se restringe aos aspectos organizacionais, estruturais, metodológicos e pedagógicos que envolvem a política de indexação, comumente na perspectiva profissional e de usuários. Os elementos destinados à elaboração de políticas de indexação indicados pela literatura especializada são considerados princípios norteadores, aspecto que acentua a ne- 
cessidade de estudos mais verticalizados sobre a questão.

Esforços estão sendo empreendidos para que o conhecimento sobre política de indexação na área de Organização e Representação do Conhecimento ganhe um delineamento sistematizado e, consequentemente, contribua para a inclusão de novos elementos que se mostrarem relevantes neste conjunto. Destaque especial seja dado às pesquisas conduzidas pelo Grupo de Pesquisa "Análise Documentária", no qual a maior parte da literatura científica do Brasil acerca da política de indexação foi desenvolvida. Num primeiro momento, as pesquisas buscaram contribuir com fundamentação teórica e metodológica, baseada no conhecimento de Ciência da Informação e áreas interdisciplinares, de modo a sistematizar uma proposta teórica e metodológica de elaboração de política de indexação com e para bibliotecas universitárias. Atualmente, os esforços são direcionados para as questões relativas ao processo de elaboração da estrutura lógica e hierárquica de linguagens de indexação na perspectiva da política de indexação.

Apesar de a literatura especializada discorrer sobre a importância da adoção de tais diretrizes, nas quais são explicitadas as escolhas técnicoadministrativas da unidade de informação pelas quais os bibliotecários indexadores precisam se orientar em suas rotinas profissionais, considerando como variáveis o usuário e o acervo, Fujita (2012) alerta sobre o desafio de aliá-las à prática cotidiana da profissão. Para a referida autora, esta associação é necessária para que haja conscientização sobre os elementos e as variáveis da política de indexação e os efeitos que estes causam na recuperação da informação. Logo, a política de indexação mostra-se imprescindível do ponto de vista gerencial e estratégico na medida em que estão subjacentes em suas diretrizes os princípios e critérios que servirão de guia na tomada de decisões, visando otimização do serviço e racionalização de processos.

Dessa forma, urge o encaminhamento de pesquisas que busquem atrelar teoria e prática profissional, considerando as questões inerentes e congruentes que envolvem estas duas esferas, ao passo que os resultados de tais investigações tendem a minimizar a barreira que separa as concepções teóricas e a prática cotidiana da profissão, propiciando o delineamento de políticas de indexação cada vez mais coerentes e passíveis de aplicação. Para tanto, entende-se que tais pesquisas precisam avançar no exame das questões de natureza cognitiva, cultural e social que permeiam a atividade de indexação, mediante a observação das particularidades advindas da vertente humana que compõe a representação temática da informação nos mais variados contextos informacionais.

$\mathrm{Na}$ atual conjuntura, a elaboração de políticas de indexação deve considerar os fundamentos teóricos e metodológicos da área de Organização e Representação do Conhecimento, a prática cotidiana da profissão e, inevitavelmente, prever a realidade específica da unidade de informação para a qual se destinam. Esta indicação demanda, por exemplo, o encaminhamento de pesquisas que observem aspectos de natureza ética presentes na atividade de indexação, até então pouco trabalhados nos elementos de política de indexação.

Este posicionamento é sustentado, dentre outros, com a perspectiva de Rubi (2008) de que a indicação de diretrizes ou a própria elaboração de políticas de indexação deve ser representada por uma filosofia que traduza os objetivos da unidade de informação e sirva de guia para os profissionais na realização da atividade de indexação, auxiliando-os para a tomada de decisões. Adicionalmente, considera-se que qualquer instrumento de trabalho que sirva de orientação para a prática profissional necessita refletir as especificidades e particularidades do ambiente de trabalho e os interesses da comunidade usuária a qual se destina.

\section{Algumas Considerações}

Abordou-se neste estudo a política de indexação e o atual cenário das pesquisas brasileiras sobre a temática. Mediante uma exposição pontual sobre os avanços obtidos, tornou-se possível discorrer sobre os principais aspectos considerados pelos estudos e os desafios a serem vencidos para a verticalização da política de indexação no âmbito teórico-conceitual, com vistas à formulação de diretrizes de cunho prático-aplicadas nos mais variados contextos de informação.

É possível apontar que a política de indexação, na condição de objeto de estudo, apresenta uma sistematização teórica e metodológica consistente, fato que favorece o avanço da pesquisa brasileira na área de Organização e Representação do Conhecimento, uma vez que as bases investigativas sobre a temática foram construídas. Todavia, é preciso atender aos vários questionamentos secundários importantes que permeiam as políticas de indexação, a fim de proporcionar acréscimos às discussões presentes no universo teórico-conceitual e, sobretudo, contribuir com novos olhares e formas 
de se pensar e elaborar diretrizes de política de indexação no âmbito prático-aplicado, considerando-se as características e particularidades dos diferentes contextos informacionais.

Diante das exposições realizadas no presente estudo, observa-se que a política de indexação configura-se um material de trabalho que demanda conhecimentos que perpassam o processo de indexação, cuja natureza complexa exige o encaminhamento de pesquisas contínuas. Nesse caminhar, registra-se a importância de novos olhares reflexivos sobre as políticas de indexação que considerem as problemáticas que envolvem a organização e representação temática da informação, bem como os fatores relacionados à gestão organizacional nas unidades de informação.

\section{Referências}

Albuquerque, M. E. B. C.; Autran, M. M. M.; Ramalho, F. A. (2011). Política de indexação da Biblioteca Digital Paulo Freire. // Brennand, Edna Maria de Góes; Albuquerque, Maria Elizabeth Baltar Carneiro de (Org.). Paulo Freire: diálogos e redes digitais. João Pessoa: Editora universitária UFPB, 2011. 67-77.

Albuquerque, M. E. B. C.; Pereira, A. R. (2007). Representação da informação de imagens paradas do Jornal da Paraíba: política de indexação. // Emeide Nóbrega Duarte; Alzira Karla Araújo da Silva. (Org.). Gestão de unidades de informação: teoria \& prática. João Pessoa: Universitária UFPB, 2007. 499-512.

Boccato, V. R. C. (2012). A linguagem documentária em catálogos on-line para política de indexação. // Gil Leiva, Isidoro; Fujita, Mariângela Spotti Lopes (Org.). Política de indexação. São Paulo: Cultura Acadêmica, 2012. 139-151.

Carneiro, M. V. (1985). Diretrizes para uma política de indexação. // Revista da Escola de Biblioteconomia da UFMG, Belo Horizonte. 14:2 (set. 1985) 221-241.

Cervantes, B. M. N.; Fujita, M. S. L.; Rubi, M. P. (2008). Terminologias em política de indexação. // García Marco, Francisco Javier (Org.). Avances y perspectivas en sistemas de información y documentación. Zaragoza: Universidad de Zaragoza, 2008. 1, 211-222.

Cesarino, M. A. N.; Pinto, M. C. M. (1978). Cabeçalho de assunto como linguagem de Indexação. // Revista da Escola de Biblioteconomia da UFMG, Belo Horizonte. 7:2 (set. 1978) 268-288.

Dal'Evedove, P. R. (2011). A Política de Tratamento da Informação na Percepção de Catalogadores de Assunto. // XXIV Congresso Brasileiro de Biblioteconomia e Documentação - CBBD. Anais: Sistemas de informação, multiculturalidade e inclusão social. Brasília: FEBAB, 2011.

Dal' Evedove, P. R.; Fujita, M. S. L. (2013). O conhecimento profissional do catalogador de assunto sobre política de indexação em bibliotecas universitárias. // Revista Digital de Biblioteconomia e Ciência da Informação. 11 (Maio/Agosto 2013) 21-39.

Dal' Evedove, P. R. (2014). O tratamento temático da informação em abordagem sociocultural: diretrizes de política de indexação em bibliotecas universitárias. Tese (Doutorado em Ciência da Informação) - Faculdade de Filosofia e Ciências, Universidade Estadual Paulista, Marília. 266f.
Fujita, M. S. L. et. al.(2007). Política de tratamento da informação documental na rede de bibliotecas universitárias da UNESP na perspectiva da Biblioteca Virtual. // XXII Congresso Brasileiro de Biblioteconomia, Documentação e Ciência da Informação. Anais do XXII Congresso Brasileiro de Biblioteconomia, Documentação e Ciência da Informação. Brasília, 2007.

Fujita, M. S. L. (2012a). A política de indexação para representação e recuperação da informação. // Isidoro Gil Leiva; Mariângela Spotti Lopes Fujita (Org.). Política de indexação. São Paulo; Marília: Cultura Acadêmica; Oficina Universitária, 2012a. 17-30.

Fujita, M. S. L. (2012b). Elaboração e avaliação da política de indexação na formação inicial do indexador. // Isidoro Gil Leiva; Mariângela Spotti Lopes Fujita (Org.). Política de indexação. 1ed. São Paulo; Marília: Cultura Acadêmica; Oficina Universitária, 2012b. 187-216.

Fujita, M. S. L. et. al. (2006a). A política de tratamento de informações da rede de bibliotecas UNESP na perspectiva do catalogador: diagnóstico com uso de protocolo verbal individual. // XIV Seminário Nacional de Bibliotecas Universitárias. Anais do XIV Seminário Nacional de Bibliotecas Universitárias. Salvador, 2006a.

Fujita, M. S. L. et. al. (2006b). O conhecimento organizacional sobre política de tratamento da informação documentária da rede de bibliotecas da UNESP: o uso do protocolo verbal em grupo/leitura como evento social como abordagem qualitativa. // XIV Seminário Nacional de Bibliotecas Universitárias. Anais do XIV Seminário Nacional de Bibliotecas Universitárias. Salvador, 2006b.

Fujita, M. S. L.; Gil Leiva, I. (2010). As linguagens de indexação em bibliotecas nacionais, arquivos nacionais e sistemas de informação na América Latina. // Seminário Nacional de Bibliotecas Universitárias. Onde estamos, para aonde vamos. Rio de Janeiro: Universidade Federal do Rio de Janeiro, 2010. 1-13.

Fujita, M. S. L.; Gil Leiva. (2009). Política de indización en latinoamerica. // García Marco, F. J. (Org.). Advances y perspectivas en sistemas de información y documentación en el entorno digital. Zaragoza: Universidad de Zaragoza. 2009. 1, 155-162.

Fujita, M. S. L.; Gil Leiva, I. (2012). Política de indexação latino-americana. // Gil Leiva, Isidoro; Fujita, Mariângela Spotti Lopes (Org.). Política de indexação. São Paulo; Marília: Cultura Acadêmica; Oficina Universitária. 2012. 121-138.

Fujita, M. S. L. (2012c). Perspectivas da política de indexação para a formação e atuação profissional de bibliotecários. // Gil Leiva, Isidoro; Fujita, Mariângela Spotti Lopes (Org.). Política de indexação. São Paulo; Marília: Cultura Acadêmica; Oficina Universitária. 2012c. 231-238.

Fujita, M. S. L.; Rubi, M. P. (2006a). A política de indexação na perspectiva do conhecimento organizacional. // VII Encuentro asociación de educadores e investigadores de bibliotecología, archivología, ciencias de la información y documentación de lberoamérica y el Caribe. Anais do VII Encuentro asociación de educadores e investigadores de bibliotecología, archivología, ciências de la información y documentación de Iberoamérica y el Caribe. Marília: FFC/UNESP-PUBLICAÇÕES, 2006a. 638654.

Fujita, M. S. L.; Rubi, M. P.; Boccato, V. R. C. (2009). O contexto sociocognitivo do catalogador em bibliotecas universitárias: perspectivas para uma política de tratamento da informação documentária. // Datagramazero. 10:2 (Abril 2009).

Fujita, M. S. L.; Rubi, M. P. (2006b). Educação à distância para formação do bibliotecário de bibliotecas universitárias do consórcio CRUESP em política de indexação: perspectivas de conteúdo e aplicação de protocolo verbal em grupo. // VII Encuentro asociación de educadores 
e investigadores de bibliotecología, archivología, ciencias de la información y documentación de Iberoamérica y el Caribe. Anais do VII Encuentro asociación de educadores e investigadores de bibliotecología, archivología, ciencias de la información y documentación de lberoamérica y el Caribe. Marília: FFC/UNESPPublicações, 2006b. 176-187.

Fujita, M. S. L.; Rubi, M. P. (2006c). Educação à distância para formação do bibliotecário de bibliotecas universitárias do consórcio CRUESP em Política de indexação: perspectivas de conteúdo e aplicação de protocolo verbal em grupo. // Seminário Nacional de Bibliotecas Universitárias. Anais do XIV Seminário Nacional de Bibliotecas Universitárias. Salvador, 2006c.

Fujita, M. S. L.; Rubi, M. P. (2007). Protocolo verbal como metodologia sociocognitiva para coleta de dados e recurso pedagógico em sala de aula. // Machado, L. M.; Maia, G. Z. A.; Labegalini, A. C. F. B. (Org.). Pesquisa em Educação: passo a passo. Marília: Ed. M3T, 2007. 143-154.

Gil Leiva, I.; Fujita, M. S. L. (Org.). (2012). Política de indexação. São Paulo: Cultura Acadêmica; Oficina Universitária. 2012.

Gil Leiva, I. (2008). Manual de indización: teoría y práctica. Gijón: Trea, 2008.

Gonçalves, M. C.; Fujita, M. S. L; Rubi, M. P. (2006). Política de indexação em sistemas de bibliotecas universitárias: levantamento de subsídios para o tratamento temático do acervo bibliográfico da UNESP. // XIV Seminário Nacional de Bibliotecas Universitárias. Anais do XIV Seminário Nacional de Bibliotecas Universitárias. Salvador, 2006.

Guimarães, J. A. C. (2004). As políticas de indexação como elementos para a gestão do conhecimento nas organizações. // Vidotti, S. A. B. G. (Org.). Tecnologia e conteúdos informacionais. São Paulo: Polis, 2004. 43-52.

Kobashi, N. Y. (1994). A elaboração de informações documentárias: em busca de uma metodologia. Tese (Doutorado em Ciências da Comunicação) - Escola de Comunicação e Artes, Universidade de São Paulo, São Paulo. 195f.

Kochani, A. P.; Boccato, V. R. C.; Rubi, M. P. (2011). Política de indexação para sistemas automatizados de coordenadorias de comunicação em ambientes universitários. // XXIV Congresso Brasileiro de Biblioteconomia, Documentação e Ciência da Informação. Maceió. Anais do XXIV Congresso Brasileiro de Biblioteconomia, Documentação e Ciência da Informação, 2011.

Lopes, I. L. (2006). Diretrizes para uma política de indexação de fotografias. // Antonio Miranda; Elmira Simeão. (Org.). Alfabetização digital e acesso ao conhecimento. Brasília: UnB/CID, 2006.

Lousada, M. et. al. Políticas de indexação no âmbito da gestão do conhecimento organizacional. // Informação \& sociedade. 21:1 (2011) 191-202.

Neves, D. A. B.; Galvino, C. C. T. (2010). Avaliação de política de indexação da Seção de Periódicos da Biblioteca Central da UFPB: pesquisa em andamento. // XI ENNANCIB. Anais do XI ENANCIB. Rio de Janeiro: IBICT, 2010. 135-141.

Nunes, C. O. (2004). Algumas considerações acerca da ausência de políticas de indexação em bibliotecas brasileiras. // Biblos. Rio Grande do Sul. 16, 55-61.

Redígolo, F. M. et. al. (2012). Elementos de política de indización para bibliotecas universitarias del área médica. // Scire (Zaragoza). 18, 75-86 (2012).

Rubi, M. P. (2004). A política de indexação na perspectiva do conhecimento organizacional. Dissertação (Mestrado em Ciência da Informação) - Faculdade de Filosofia e Ciências, Universidade Estadual Paulista, Marília. 135 f.
Rubi, M. P. et. al. (2007). Política del tratamiento de la información documentaria en bibliotecas universitarias: estudio diagnóstico del contexto en la perspectiva del catalogador y del usuario. // Francisco Javier García Marco. (Org.). Revista de sistemas de información y documentación. Zaragoza: Ibersid, 2007. 71-80.

Rubi, M. P.; Fujita, M. S. L.; Boccato, V. R. C. (2012a). Del conocimiento tácito al explicito: elaboración de un manual de política de indización en bibliotecas universitarias. // Scire (Zaragoza). 18:2 (2012a), 67-74.

Rubi, M. P.; Fujita, M. S. L.; Boccato, V. R. C. (2012b). Elaboração do manual de política de indexação na formação continuada do catalogador. // Gil Leiva, Isidoro; Fujita, Mariângela Spotti Lopes (Org.). Política de indexação. São Paulo: Cultura Acadêmica, 2012b. 217-227.

Rubi, M. P.; Fujita, M. S. L. (2003a). Elementos de política de indexação em manuais de indexação de sistemas de. // Perspectivas em Ciência da Informação, Belo Horizonte. 8:8 (2003a) 57-66.

Rubi, M. P.; Fujita, M. S. L. (2007). La política de indización en la perspectiva del conocimiento organizacional. // Blanca Rodríguez Bravo; Maria Luisa Alvite Diez. (Org.). La interdisciplinariedad y la transdisciplinariedad en la organización del conocimiento científico. León: Universidad de León, 2007, 1, 451-458.

Rubi, M. P.; Fujita, M. S. L. (2006). O ensino de procedimentos de política de indexação. // Perspectivas em Ciência da Informação, Belo Horizonte. 11:1 (2006) 48-66.

Rubi, M. P.; Fujita, M. S. L. (2010). Política de indexação na catalogação de assunto em bibliotecas universitárias: a visão sociocognitiva da atuação profissional com protocolo verbal. // Revista Digital de Biblioteconomia e Ciência da Informação. 7 (2010) 168-200.

Rubi, M. P.; Fujita, M. S. L. (2003b). Política de indexação na visão dos indexadores. // V Encontro Nacional de Pesquisa em Ciência da Informação. Anais do V Encontro Nacional de Pesquisa em Ciência da Informação. Belo Horizonte: ENANCIB, 2003b.

Rubi, M. P. (2000). Os serviços de análise e sua política de indexação. Trabalho de Conclusão de Curso (Graduação em Biblioteconomia) - Faculdade de Filosofia e Ciências, Universidade Estadual Paulista, Marília. 80f.

RUBI, M. P. (2012a). Política de indexação. // Gil Leiva, Isidoro; Fujita, Mariângela Spotti Lopes (Org.). Política de indexação. São Paulo: Cultura Acadêmica, 2012a. 107-120.

Rubi, M. P. (2009). A indexação de livros: a percepção de catalogadores e usuários de bibliotecas universitárias. // Fujita, Mariângela Spotti Lopes (Org.). Os princípios da política de indexação na análise de assunto para catalogação: especificidade, exaustividade, revocação e precisão na perspectiva dos catalogadores e usuários. São Paulo: Cultura Acadêmica, 2009. 81-94.

Rubi, M. P. (2008). Política de indexação para construção de catálogos coletivos em bibliotecas universitárias. Tese (Doutorado em Ciência da Informação) - Faculdade de Filosofia e Ciências, Universidade Estadual Paulista, Marilia. $169 f$.

Rubi, M. P. Proposta para implantação de política de indexação em bibliotecas. // Gil Leiva, Isidoro; Fujita, Mariângela Spotti Lopes (Org.). Política de indexação. São Paulo: Cultura Acadêmica, 2012b. 171-183.

Silva, L. C. de O.; Santos, C. A. C. M. (2012). Proposta metodológica para o estabelecimento de política de indexação para a biblioteca escolar. // CRB-8 Digital, 5 (2012) 173-182.

Enviado: 2015-04-01. Segunda versión: 2015-06-09. Aceptado: 2015-06-16. 